\title{
Integrating high levels of variable renewable energy into electric power systems
}

\author{
Benjamin KROPOSKI ${ }^{1}$ (])
}

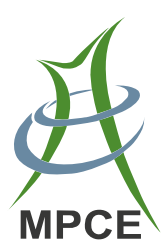

\begin{abstract}
As more variable renewable energy (VRE) such as wind and solar are integrated into electric power systems, technical challenges arise from the need to maintain the balance between load and generation at all timescales. This paper examines the challenges with integrating ultrahigh levels of VRE into electric power system, reviews a range of solutions to these challenges, and provides a description of several examples of ultra-high VRE systems that are in operation today.
\end{abstract}

Keywords High penetration, Variable renewable energy, Grid operation, Wind, Solar

\section{Introduction}

Over the last 100 years, electric power systems have developed in a way where dispatchable generation is used to provide electricity when customer loads demanded it. The primary energy sources used in disptachable generation includes generation from coal, nuclear, hydropower, diesel, and natural gas plants. These sources are able to store some amount of the primary energy source on site and then generate electricity to meet demand needs. One key feature of these conventional sources is the use of

CrossCheck date: 27 October 2017

Received: 10 September 2017/Accepted: 27 October 2017/Published online: 17 November 2017

(C) The Author(s) 2017. This article is an open access publication

$\triangle$ Benjamin KROPOSKI

benjamin.kroposki@nrel.gov

1 National Renewable Energy Laboratory, Golden, CO 80401, USA synchronous generators as the point of connection to the electrical power system. A synchronous generator is used to develop a 50 or $60 \mathrm{~Hz}$ alternating current (AC) waveform of electricity. AC was chosen over a century ago as a preferred method of producing and moving electricity mostly because of the ability to transmit AC power over long distances at very high voltage and relatively low current levels. This was the most economic transmission method because of the minimization of conductor size and because the transmission losses are proportional to the square of the current. This characteristic enabled largescale central station power plants to be built far from load centers and the electricity was transferred via high voltage $\mathrm{AC}$ transmission lines. Innovations in the design and use of AC power grids have allowed them to become the dominant system design for power grids around the world.

During the last 30 years, there has been significant increase in the use of wind and solar power generation. These technologies offer a free fuel source but are variable in nature and only produce power when there are solar or wind resources. Therefore, we call them variable renewable energy (VRE). Wind and solar photovoltaic (PV) do not naturally have on-site energy storage, so their output is typically referred to as non-dispatchable. Other characteristics that make VRE integration a challenge are the uncertainty associated with their output and asynchronous nature of interconnection to the grid. As costs for wind and solar continue to decrease and regulations require the use of more clean energy technologies, there is a need to understand the technical challenges and develop solutions to integrate ultra-high levels of VRE into electrical power systems. This paper defines ultra-high levels as VRE penetrations over $50 \%$ on an annual energy basis across a synchronous power system and up to $100 \%$ on an instantaneous basis. The annual penetration level is an average of 
the amount of energy the VRE produce (Wh) divided by the total amount of energy (Wh) needed for an entire year. Instantaneous penetration refers to the VRE power output (W) divided by the total power requirement (W) at any point in time. Instantaneous penetration can vary considerably during the course of a day depending on the available renewable resources and the electricity load.

One of the unique features of PV and wind turbines is that they are typically designed using a power electronic interface to the grid called an inverter instead of a synchronous generator. This is because a PV system naturally produces DC electricity and most new wind turbine designs use some type of power electronics to convert the nonsynchronous rotation of wind turbines into AC waveforms compatible with the power grid. The inverter converts direct current (DC) electricity to grid compatible AC power. Discussion on the design of inverters for renewable and distributed energy applications can be found in the references [1-4].

The development of advanced inverter technologies over the last thirty years has allowed both PV and wind technologies to be easily integrated into AC electrical grids, however they do have different characteristics from synchronous generators and therefore have unique challenges with this integration [5]. One difference is the inherent inertia that a large rotating mass from a synchronous generator can provide. This rotating inertia helps synchronous generators ride through voltage and frequency deviations in the grid caused by abnormal operations such as a fault. As more synchronous generators in a power system are replaced by inverter based VRE, the inverters will need to be able to provide "synthetic" inertia that mimics the characteristics of synchronous generators. Current power electronics can be designed to provide this as well as a large array of ancillary services that are needed to support reliable grid operations [6-8].

\section{Power system operations}

With all AC power systems the main technical challenge is to maintain proper voltage and frequency at all timescales and deliver electrical power to loads. This ensures stable and reliable operation. The power system must also be able to maintain safe operations within a number of physical limits including voltage and current levels. Figure 1 from [9] shows a generic daily load curve for a power system, with system load (MW) increasing during the middle of the day and lowering at night. At all time periods during this day, the demand must be satisfied with power from generation or storage.

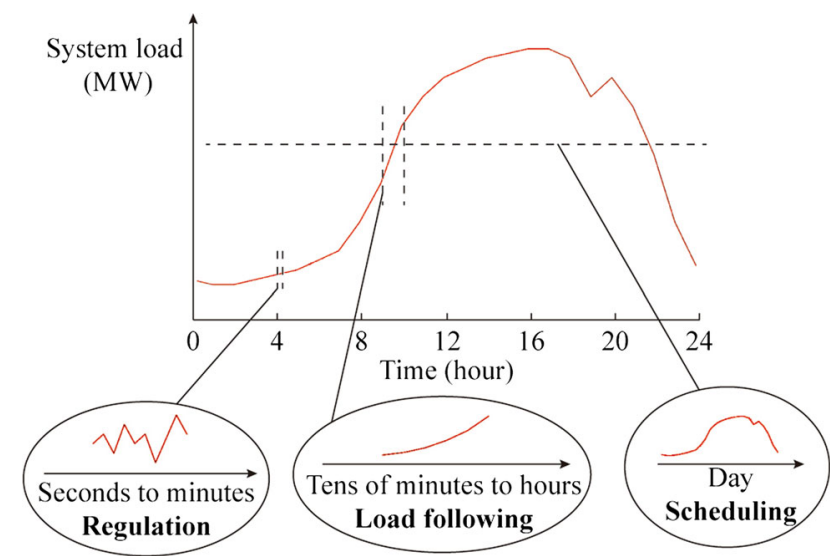

Fig. 1 Power system generic daily load curve

\subsection{Regulation}

The fast response to disturbances or load changes is called regulation because you are regulating the frequency of the AC power system. This is done continuously throughout the day and focuses on the fast timescales from instantaneous to minutes. To maintain proper frequency in an $\mathrm{AC}$ power system, generators need to be able to respond instantaneously to events that require more or less power (load changes). This is referred to as the primary frequency response or inertial response. The physical characteristics of the generator dictate how fast a synchronous generator can respond during an abnormal event and if it can return to a steady-state frequency. Secondary response from generators is then used to correct the frequency to its pre-event levels. In large systems, the use of automatic generator controls (AGC) brings a signal to the generators in a system to correct the frequency back to nominal value [10]. A tertiary response may be needed to protect the system against possible subsequent events when both primary and secondary responses have been depleted. The main challenge with this area is that since power electronic based inverters do not have any physical rotating mass, they can impact the overall inertial response of a synchronous power system. New studies have shown that both wind and solar can provide these fast regulation services and in some cases can respond faster than synchronous generators $[6-8,11]$.

\subsection{Load following}

Load following in a power system occurs throughout the day and happens on the order of minutes to hours. To follow the natural increase or decrease in demand over hours, the power from generation is slowly increased or decreased (or new generation is brought on/off line) to meet the load. This service is usually provided by generation with relatively fast ramping capabilities or the ability 
to turn on/off in tens of minutes. Since VRE produce power when renewable resources are available, they are not typically designed to follow load unless paired with some type of energy storage. When adding ultra-high levels of VRE into power systems, special attention must be paid to the overall net load after VRE is accounted for. In some cases, the new ramping requirements may be considerable different that the original system requirements [12].

\subsection{Scheduling}

Scheduling in a power system is the planning for generation to meet the daily energy and peak power requirements. This often involves forecasting the demand for the day and scheduling what generation will meet that demand at a coarse level with adequate reserve margins. Since scheduling is intricately connected to forecasts of the generation output and availability, being able to forecast variable renewable resources is critical in systems with ultra-high levels of VRE.

\section{Challenges and solutions to integrate VRE}

There are a variety of challenges to integrate high levels of VRE into electric power systems. This section will discuss some of those challenges focusing on operational considerations and also review a range of possible solutions. The solutions are always system and location dependent and may or may not be applicable to certain situations.

The main attribute of VRE that must be addressed is the variability of the resource and how to account for this variability over several time scales. Since VRE is not dispatchable, there are a number of technical opportunities to create grids that are more flexible and can accommodate higher levels of VRE. Cochran et al. [13] describe a number of integration options and how they can increase the amount of VRE in power systems.

\subsection{Geographic diversity of variable resource}

It is important to understand the benefits of geographic diversity of variable resources. As you spread the VRE across an area, there is a marked decline in the system-wide variability. Numerous studies have examined how the system-wide variability is reduced for both wind and solar $[14,15]$. This is only possible as the interconnected system size increases and some small systems may not have any way to increase the geographic diversity of their system. Another interesting point on diversity is that there is often complimentary nature of wind and solar depending on location [16, 17]. These can be both daily and seasonal complements.

\subsection{Renewable forecasting}

Being able to forecast the VRE output is critical to operate ultra-high renewable systems unless significant reserve margins are designed to account for not being able to predict the future VRE output. Forecasting can have different impacts and values at different forecasting horizons, ranging from day-ahead to minutes-ahead [18]. The renewable resource forecasting acts like a scheduling mechanism used for dispatchable generation. Accurate forecasting of VRE output can significantly reduce reserve margins and ensure the most economic systems. New forecasting techniques have shown increased value beyond persistent forecasting and the value of renewable forecasting has been studied for integrating higher penetrations of VRE [19, 20].

\subsection{Generator flexibility}

Generator flexibility includes the ability of the generator to ramp power up and down and operate at low output levels. The ramping capability of existing generation is an important consideration when trying to balance load and available generation. Since large amounts of VRE can cause large changes in the net loads seen by other generators, it is important that there are available ramping capabilities. The minimum load on existing generators is also another important consideration since it is usually a determining factor as to how much VRE can be run at any particular point in time.

\subsection{Energy storage}

Energy storage is very important in the systems with ultra-high levels of VRE. Energy storage can be used for a variety of functions including regulation, load following, and energy shifting to add or absorb energy from a power system when there is too little or too much renewable energy. There are a variety of energy storage options that can be included in electric power systems and detailed discussion can be found in [21]. In large-scale power systems the amount of energy storage to reach ultra-high levels of VRE while large, can be a relatively small fraction of the overall system size. A study conducted by the National Renewable Energy Laboratory called the Renewable Electricity Futures (REF) study [22] showed that to reach a $90 \%$ renewable energy scenario that included $48 \%$ wind and solar required around $140 \mathrm{GW}$ of installed storage capacity, as shown in Fig. 2. 


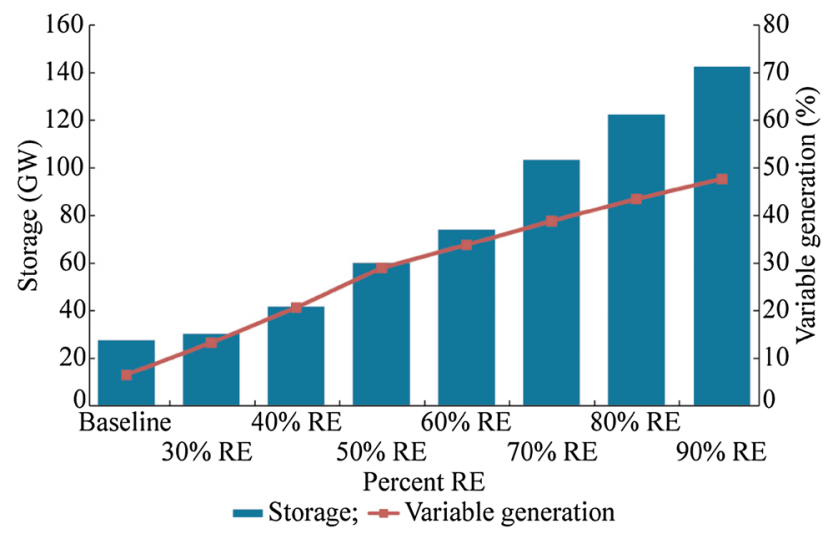

Fig. 2 Storage versus percent renewable energy

The REF study looked at the entire continental United States' electricity needs in 2050 of around $4126 \mathrm{TWh}$ of load being met with around $1400 \mathrm{GW}$ of installed capacity from nuclear, renewable, and fossil fuel sources. The energy storage on a capacity basis is around $10 \%$ of the total installed capacity. The storage used in this study was a combination of pumped hydro storage and compressed air. In this case, the system's storage is mostly used for daily load balancing and not to support any days of autonomy. Days of autonomy are the number of days that a power system can operate without wind or solar power.

On smaller systems for example the Hawaiian island of Lanai, a study [23] showed that much more energy storage is needed to reach ultra-high levels of VRE. To reach $88 \%$ VRE on an annual energy basis required $16 \mathrm{MW}$ of PV to supply the total annual load of 30244 MWh per year with a peak demand of $4.9 \mathrm{MW}$. The system also required $84 \mathrm{MWh}$ of storage, which is fairly large compared to the overall load. The amount of energy required under this study is high because the limited fuel diversification and relatively low capacity factors for PV (around 20\%). Less storage was needed when the system was designed using wind in place of PV since the wind resource had a higher capacity factor, less daily variability, and provided more renewable energy during the course of a year.

\subsection{Curtailment}

Due to the fact that wind and solar have relatively low capacity factors compared to other generation sources, they must be over-built in terms of capacity to supply enough energy for ultra-high penetration levels. One challenge is that sometimes it is not feasible to store or use all of this excess energy and it must be reduced or curtailed. The curtailment of both PV and wind is relatively easy to achieve since PV systems can be operated off of their maximum power point all the way to zero output. Wind turbines can be curtailed by a number of mechanisms including furling the blades and even braking the turbine rotors. Curtailed energy in smaller isolated systems can also be dissipated in dump loads that consist of banks for resistors. The excess energy in dump loads is often used to heat water since this is the natural byproduct. Larger system studies have shown that curtailed energy does not necessarily have to be significant. The REF study [22] showed that even at high levels of $90 \%$ RE/48\% VRE, the total amount of curtailed wind and solar was only $7 \%$ of the total energy, as shown in Fig. 3.

\subsection{Load control}

Another option to increase the amount of VRE is to shift demand through load control. Instead of designing grids to deliver energy when loads demand it, a system can be designed to use energy when there is available power from VRE. In this case, the generation won't follow loads. Instead, the load starts to follow the generation. Controllable loads can be used to shift power and energy usage throughout the day and in some cases act as storage by preheating or precooling the thermal mass of buildings. Reference [24] have shown that using responsive loads is one of the most underutilized reliability resources and has the potential to provide balancing capability over all time frames from seconds to seasons.

\subsection{Other considerations}

In large systems, additional ways to increase system flexibility to integrate higher levels of VRE include improving joint operations of adjacent power systems as a way to share resources, additional grid infrastructure built outs to remove congestion and constraints, and market mechanisms that improve overall economics and incentivize flexibility.

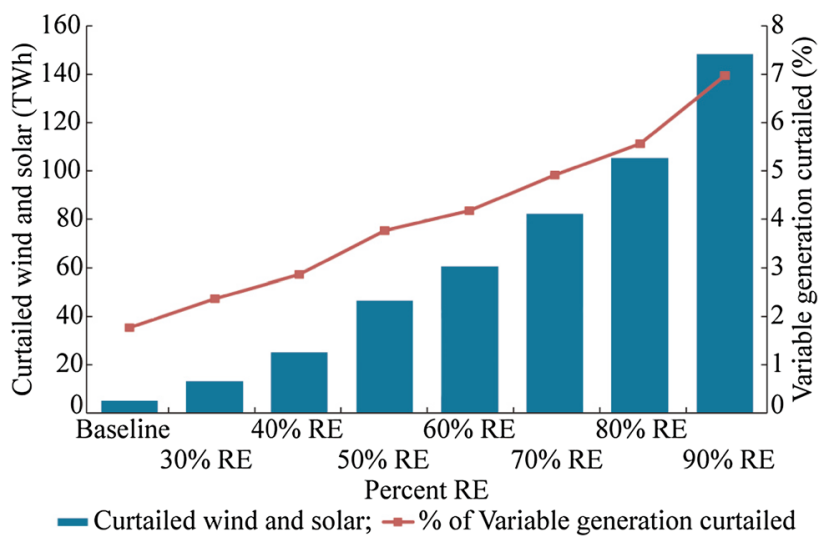

Fig. 3 Curtailed electricity versus percent renewable energy 


\section{Examples of VRE penetrations in power grids}

AC power systems can range in size from very small single households to continental systems that stretch over large land areas. The physical size of the electric power system has had an impact on the amount of VRE integrated into grids to date. Figure 4 shows a graph of currently operating power systems with capacities ranging from $100 \mathrm{~kW}$ to $1000 \mathrm{GW}$ and amount of VRE on an annual basis that has been integrated.

The smaller systems are true synchronous AC grids with ultra-high levels of renewables. These are mostly very small systems under $1 \mathrm{MW}$ of installed capacity that are located in remote areas and island power systems. At the very small end of the spectrum are island like Ta'u in America Samoa located in the South Pacific. This island recently replaced its diesel generators with a $1.4 \mathrm{MW}$ PV system and 6 MWh battery system [25]. The average load is only around $80 \mathrm{~kW}$. The reason that the installed capacity for the PV and battery is so much higher than the average load is because the system must be sized to fully meet its energy needs with only solar energy and the capacity factor for solar even in the best locations is around $20 \%$. So to produce enough power for 24-h operations a PV system would need to be sized at least 5 times larger than the load on a daily basis. The PV and energy storage must also be designed to provide several days of power when there is no sun.

Remote villages often operate with high levels of VRE. These systems are mainly wind-diesel-battery hybrid power systems. Examples of these small types of systems can be found throughout the world. VRE is often integrated into these systems to reduce diesel fuel usage since it is costly to bring fuel to these remote locations. An example

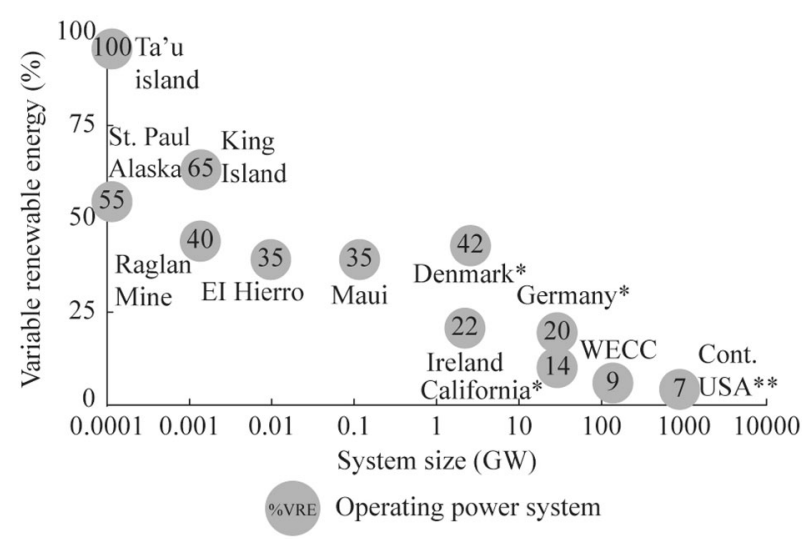

Note: * Part of a larger synchronous AC power system

** Contains 3 synchronous AC power systems

Fig. 4 Variable renewable energy versus system size of such a system is in St. Paul, Alaska [26, 27]. This system has an average load of $70 \mathrm{~kW}$ and operates with $55 \%$ annual penetration of wind and instantaneous penetrations over $100 \%$. Another Alaskan Island-Kodiak Island-also operates with high levels of renewable energy. It integrated around $20 \%$ wind, but heavily relies on hydropower $(80 \%)$ as a way to balance its needs [28].

Another application for power systems with high levels of VRE mines in remote locations. The Raglan mine in northern Canada uses wind to provide about $40 \%$ of its annual energy [29]. The Raglan mine has $3 \mathrm{MW}$ of wind and 1.6 MW of diesel with and average load of 1.4 MW.

Two islands between Australia and Tasmania also operate with very high levels of variable renewable energy. Flinders Island operates with $60 \%$ and King Island operates with $65 \%$ variable renewables. King Island has a $3 \mathrm{MW}$ peak load and operates a $65 \%$ annual renewable generation and is evaluating using biodiesel to get to $100 \%$ renewable energy [30]. Another system of similar size is El Hierro, one of the Canary Islands off the coast of northwestern Africa. El Hierro aimed to be the world first $100 \%$ renewable energy island but currently operates at around $35 \%$ VRE and uses a significant amount of hydropower and pump hydro storage to balance supply and demand [31]. El Hierro's peak load is 7.5 MW and average load is around $4 \mathrm{MW}$.

In the United States, the island of Maui reached over $35 \%$ wind and solar energy in 2016 [32]. This is a mix of both large-scale wind plants and smaller distributed and customer-sited PV and wind systems. Maui's peak load is around $200 \mathrm{MW}$ and with an average load of $80 \mathrm{MW}$.

There are very few actually operating synchronous power systems above $1 \mathrm{GW}$ that have over $20 \%$ VRE. One example is the country of Ireland. Ireland has a peak electricity demand of around $6.5 \mathrm{GW}$ and an average demand of $5.5 \mathrm{GW}$. It reached $21.3 \%$ annual wind penetration in 2016 and allows the system to operate at up to $60 \%$ instantaneous penetration. Ireland has a target of reaching $40 \%$ renewable electricity by 2020 and has done a large amount of work on integrating non-synchronous energy sources to their grid [33].

Other areas in the figure are worth note. Denmark reached $42 \%$ penetration of VRE, Germany $20 \%$, and California $14 \%$ in 2015, but these areas are parts of larger synchronous AC grids and can ship excess power from VRE to neighboring regions and rely on the overall system for stability support. Larger synchronous AC systems, such as the Western Interconnection of the United States that is coordinated for reliability by the Western Electrical Coordinating Council (WECC) are only around 14\% wind and solar by capacity and $9 \%$ by annual energy [34]. The WECC power system has a peak demand of approximately $150 \mathrm{GW}$. Studies have been conducted to examine the 
impacts of high levels of VRE in the WECC [35]. These studies have shown that $35 \%$ on an annual basis and $65 \%$ on an instantaneous basis are technically possible.

The final point on the graph is for the continental United States. It reached around 7\% VRE in 2016 [36]. One note is that the United States power grid is actually made up of three separate synchronous grids connected with back-toback DC ties.

\section{Conclusion}

As higher levels of VRE are integrated into electric power system, the main technical challenges deal with variability, uncertainty, and asynchronous operations. There are a variety of key technologies and management measures that can be used to increase the penetration levels of VRE. Geographic diversity, flexible conventional generation, load control, and curtailment can be used to deal with variability. Better renewable forecasting can help with uncertainty in generation and reserves. Energy storage can help deal with all aspects of the integration challenge, but also is one of the most expensive options. At the very highest levels of VRE penetration, energy storage is crucially important to allow for significant energy shifting and grid availability when the renewable resource is not available. In order to provide enough energy, VRE systems may need to be oversized and may require significant curtailment during some parts of the day. As the penetration of VRE increases, there is also typically a need to increase both energy storage requirements and the amount of energy that is curtailed due to over-production at certain times during the day. Another critical issue is that VRE will also need to be designed to provide a full range of essential grid reliability services to ensure system stability. This means that there must be some device (either the VRE or energy storage devices) that needs to be like a voltage source when there is not enough synchronous generation to maintain a voltage reference and respond to voltage and frequency deviations.

This paper also examined several real-world operating systems that operate at high levels of VRE penetration and showed that ultra-high levels have been achieved at small to medium sized grids. These systems often have very large VRE and energy storage compared to the load to account for operations during several days of low wind or solar availability. This should lay the foundation for how to achieve ultra-high levels of VRE at large-sized grids.

Acknowledgements This work was supported by the U.S. Department of Energy under Contract No. DE-AC36-08GO28308 with Alliance for Sustainable Energy, LLC, the Manager and Operator of the National Renewable Energy Laboratory. The U.S. Government retains and the publisher, by accepting the article for publication, acknowledges that the U.S. Government retains a nonexclusive, paidup, irrevocable, worldwide license to publish or reproduce the published form of this work, or allow others to do so, for U.S. Government purposes.

Open Access This article is distributed under the terms of the Creative Commons Attribution 4.0 International License (http:// creativecommons.org/licenses/by/4.0/), which permits unrestricted use, distribution, and reproduction in any medium, provided you give appropriate credit to the original author(s) and the source, provide a link to the Creative Commons license, and indicate if changes were made.

\section{References}

[1] Blaabjerg F, Chen Z, Kjaer SB (2004) Power electronics as efficient interface in dispersed power generation systems. IEEE Trans Power Electron 9(5):1184-1194

[2] Chakraborty S, Kramer SB, Kroposki B (2009) A review of power electronics interfaces for distributed energy systems towards achieving low-cost modular design. Renew Sustain Energy Rev 13:2323-2335

[3] Kroposki B, Pink C, DeBlasio R et al (2010) Benefits of power electronic interfaces for distributed energy systems. IEEE Trans Energy Convers 25(3):901-908

[4] Blaabjerg F, Yang Y, Ma K et al (2015) Power electronics-the key technology for renewable energy system integration. In: Proceedings of 4th international conference on renewable energy research and applications, Palermo, Italy, 2015, 11pp

[5] Kroposki B, Johnson B, Zhang Y et al (2017) Achieving a 100\% renewable grid-operating electric power systems with extremely high levels of variable renewable energy. IEEE Power Energy Mag 15(2):61-73

[6] Gevorgian V, O’Neill B (2016) Demonstration of active power controls by utility-scale PV power plant in an island grid. In: Proceedings of 15th international workshop on large-scale integration of wind power into power systems as well as on transmission networks for offshore wind power plants, Vienna, Austria, November 15-17, 2016, 7pp

[7] Gevorgian V, Koralewicz P, Wallen R et al (2016) Controllable grid interface for testing ancillary service controls and fault performance of utility-scale wind power generation. In: Proceedings of 15 th international workshop on large-scale integration of wind power into power systems as well as on transmission networks for offshore wind power plants, Vienna, Austria, 15-17 November 2016, 8pp

[8] Loutan C, Klauer P, Chowdhury S et al (2017) Demonstration of essential reliability services by a $300-\mathrm{MW}$ solar photovoltaic power plant. National Renewable Energy Laboratory (NREL), Golden

[9] Parsons B (2006) Grid Impacts of wind power variability: recent assessments from a variety of utilities in the United States. National Renewable Energy Laboratory (NREL), Golden

[10] Jaleeli N, VanSlyck L, Ewart D et al (1992) Understanding automatic generation control. IEEE Trans Power Syst 7(3):1106-1122

[11] Nelson A, Nagarajan A, Prabakr K et al (2016) Hawiian electric advanced inverter grid support function laboratory validation and analysis. National Renewable Energy Laboratory (NREL), Golden

[12] Milligan M, Frew B, Zhou E et al (2015) Advancing system flexibility for high penetration renewable integration. National Renewable Energy Laboratory (NREL), Golden 
[13] Cochran J, Miller M, Zinaman O et al (2014) Flexibility in 21st century power systems. 21st century power partnership. National Renewable Energy Laboratory (NREL), Golden

[14] Mills A, Ahlstrom M, Brower M et al (2012) Dark shadows. IEEE Power Energy Mag 9(3):33-41

[15] Fisher S, Schoof J, Lant C et al (2013) The effects of geographical distribution on the reliability of wind energy. Appl Geogr 40:83-89

[16] Hoicka C, Rowlands I (2011) Solar and wind resource complementarity: advancing options for renewable electricity integration in Ontario, Canada. Renew Energy 36(1):97-107

[17] Monfortia F, Hulda T, Bódisa K et al (2014) Assessing complementarity of wind and solar resources for energy production in Italy: a Monte Carlo approach. Renew Energy 63:576-586

[18] Martinez-Anido CB, Botor B, Florita AR et al (2016) The value of day-ahead solar power forecasting improvement. Solar Energy 129:192-203

[19] Cui MJ, Zhang J, Hodge BM et al (2017) A methodology for quantifying reliability benefits from improved solar power forecasting in multi-timescale power system operations. IEEE Trans Smart Grid PP(99):1-1

[20] Wang Q, Wu H, Florita A et al (2016) The value of improved wind power forecasting: grid flexibility quantification, ramp capability analysis, and impacts of electricity market operation timescales. Appl Energy 184:696-713

[21] Akhil A, Huff G, Currier A et al (2013) DOE/EPRI 2013 electricity storage handbook in collaboration with NRECA. Sandia Report, SAND2013-5131

[22] Hand MM, Baldwin S, DeMeo E et al (2012) Renewable electricity futures study. National Renewable Energy Laboratory (NREL), Golden

[23] Kroposki B, Burman K, Keller J et al (2012) Integrating high levels of renewables into the Lanai Electric Grid. National Renewable Energy Laboratory (NREL), Golden

[24] NREL, Kirby B, Milligan M (2010) Utilizing load response for wind and solar integration and power system reliability. National Renewable Energy Laboratory (NREL), Golden

[25] Rive P (2016) Island in the Sun. http://blog.solarcity.com/islandin-the-sun/. Accessed 22 Nov 2016

[26] DOE (2009) Systems performance analyses of Alaska winddiesel projects-St. Paul, Alaska. Department of Energy (DOE), Washington DC, USA

[27] Fay G, Schworer T, Keith K (2010) Alaska isolated wind-diesel systems: performance and economic analysis. Prepared for Alaska Energy Authority and Denali Commission. http://www.iser.uaa. alaska.edu/Publications/wind_diesel10022010.pdf. Accessed 10 June 2010

[28] Kodiak Electric (2015) Association Kodiak Electric Association Statistics. http://kodiakelectric.com/generation.html. Accessed 6 May 2015
[29] TUGLIQ Energy Co. (2016) Glencore RAGLAN mine renewable electricity smart-grid pilot demonstration. https://www. nrcan.gc.ca/energy/funding/current-funding-programs/eii/16662. Accessed 16 Nov 2016

[30] Gamble S (2017) 100\% renewable energy for islands: King and Flinders island case studies. https://www.kangarooisland.sa.gov. au/webdata/resources/files/4\%20\%20HydroTasmania_Simon Gamble_Kangaroo\%20Island\%20Presentation.pdf. Accessed 15 Apr 2017

[31] Jargstorf B (2017) An independent evaluation of the El Hierro Wind \& Pumped Hydro System. http://euanmearns.com/anindependent-evaluation-of-the-el-hierro-wind-pumped-hydrosystem/. Accessed 23 Feb 2017

[32] Maui Electric (2017) Renewable portfolio standard complianceMaui Electric. https://www.mauielectric.com/clean-energyhawaii/clean-energy-facts/wind-energy-integration. Accessed 14 Aug 2017

[33] O'Sullivan J, Coughlan Y, Rourke S et al (2012) Achieving the highest levels of wind integration: a system operators perspective. IEEE Trans Sustain Energy 3(4):819-825

[34] WECC (2017) State of the interconnection digest. https://www. wecc.biz/epubs/StateOfTheInterconnection/. Accessed $11 \mathrm{Sept}$ 2017

[35] Miller N, Leonardi B, Aquila RD et al (2015) Western wind and solar integration study phase 3A: low levels of synchronous generation. National Renewable Energy Laboratory (NREL), Golden

[36] EIA (2017) US energy information administration-wind and solar in march accounted for $10 \%$ of US electricity generation for first time. https://www.eia.gov/todayinenergy/detail.php?id= 31632. Accessed 14 June 2017

Benjamin KROPOSKI is the Director of the Power Systems Engineering Center at the National Renewable Energy Laboratory (NREL) where he leads NREL's strategic research in the design, planning and operations of electrical power systems. He received his BS and MS in Electrical Engineering from Virginia Tech and Ph.D. from the Colorado School of Mines. His expertise is in the design, testing, and integration of renewable and distributed power systems and has more than 125 publications in these areas. As an IEEE Fellow, Dr. Kroposki was recognized for his leadership in renewable and distributed energy systems integration. He has served on a number of IEEE technical standards working groups and chaired IEEE 1547.4, the first international standard on microgrids. 